\title{
Medisinstudenters holdninger til legalisering av eutanasi og legeassistert selvmord
}

\begin{abstract}
BAKGRUNN Vi ønsket å undersøke hvilke holdninger kommende leger har til legalisering av eutanasi og legeassistert selvmord. Spørsmålet er viktig fordi en eventuell lovfesting av disse praksisene vil gi legene en helt ny rolle.
\end{abstract}

MATERIALE OG METODE Holdningene ble kartlagt med en spørreskjemaunders økelse blant 5. og 6. års medisinstudenter ved de fire norske studiestedene.

RESULTATER 531 studenter svarte $(59,5 \%$ av totalt antall studenter på kullene). Av disse mente 102 (19\%) at eutanasi burde legaliseres ved terminal sykdom og 164 (31\%) at legeassistert selvmord burde tillates for denne indikasjonen. 145 (28\%) oppga at de ikke visste. Et mindretall av respondentene ville tillate eutanasi eller legeassistert selvmord $i$ andre situasjoner. Kvinner og de som oppga at religion var viktig, var mindre positive til å tillate eutanasi eller legeassistert selvmord enn menn.

FORTOLKNING I de fleste beskrevne situasjoner er flertallet av studentene avvisende til legalisering. Ved terminal sykdom er meningene mer delte, ettersom en større andel støtter legalisering og flere er usikre.

De nederlandske definisjonene av eutanasi og legeassistert selvmord har i dag status som internasjonal konvensjon (1). Disse er gjengitt i ramme 1 (2), og de innebærer at begrepsparet «aktiv/passiv eutanasi» så å si er utgått på dato. Noen argumenterer for at det tilsvarende norske «aktiv/passiv dødshjelp» ikke lenger bør brukes - også fordi denne terminologien tilslører skillet mellom injeksjon eller oralt inntak av dødbringende medikamenter og behandlingsbegrensning (3).

Eutanasi og legeassistert selvmord er regulert i egne lover i Nederland, Belgia og Luxembourg (1). I USA tillater delstatene Oregon, Washington, Montana og Vermont legeassistert selvmord $(4,5)$. I den sveitsiske straffeloven er det ikke noe forbud mot «uegennyttig» assistert selvmord, og dette kan også utføres av lekfolk (1).

Undersøkelser i Norge har vist at et stort flertall av helsepersonell er negative til legalisering, mens et flertall i befolkningen tilsynelatende er positive (tab 1) (6-11). Blivende norske legers syn på dette temaet vil kunne påvirke kliniske og etiske oppfatninger på feltet, og det er følgelig interessant å kartlegge hva de mener. I tillegg kan deres oppfatninger ha politiske konsekvenser ved å innvirke på lovgivningen, enten i mer restriktiv eller i mer liberal retning. En eventuell legalisering vil gi leger en helt ny rolle.

Den offentlige debatten må være informert om helsepersonells holdninger. Vi ønsket også å undersøke sammenhengen mellom religiøs tilhørighet og holdninger. Tradisjonelt har kristendommen og islam avvist eutanasi og legeassistert selvmord (12), men det er uvisst i hvilken grad dagens kristne og muslimske medisinstudenter støtter det tradisjonelle synet.

Målet for undersøkelsen var å kartlegge fremtidige legers holdninger til eutanasi og legeassistert selvmord, ved hjelp av et spørreskjema.

\section{Materiale og metode \\ Populasjon og inklusjon}

Våren 2012 ble et spørreskjema distribuert til 5. og 6. års medisinstudenter ved de fire norske medisinske fakultetene. Utvalget besto av tre studentkull fra Oslo, tre fra Bergen, to fra Trondheim og ett fra Tromsø, totalt ni kull med til sammen 893 studenter. Spørreskjemaet ble delt ut og besvart i pausen mellom to forelesningstimer. Bare de som var på forelesning, fikk mulighet til å delta. Et informasjonsskriv om at deltakelsen var frivillig og besvarelsene anonyme fulgte med skjemaet.

I utformingen av spørreskjemaet vektla vi å bruke mest mulig presise og nøytrale begreper og å unngå ledende spørsmålsformuleringer. Spørreskjemaet ble innledet slik: «I Nederland er eutanasi og legeassistert selvmord tillatt ved somatisk og psykiatrisk sykdom med uutholdelig lidelse uten utsikt til forbedring. Ta stilling til følgende påstander angående Norge.» Respondentene ble spurt om eutanasi og/eller legeassistert selvmord burde tillates $\mathrm{i}$ fem ulike situasjoner (tab 2). De ble også bedt om å oppgi kjønn, religion og hvor viktig religionen var for dem. Definisjonene i ramme 1 var gjengitt i spørreskjemaet.

\section{Statistikk}

Resultatene presenteres deskriptivt med angivelse av antall og prosent. De statistiske

\author{
Magnus Andreas Nordstrand \\ nordstrand.ma@gmail.com \\ Sven Jakob Nordstrand \\ Senter for medisinsk etikk \\ Universitetet i Oslo
}

\section{Lars Johan Materstvedt}

Institutt for filosofi og religionsvitenskap

Norges teknisk-naturvitenskapelige universitet

\section{Per Nortved}

Senter for medisinsk etikk

Universitetet i Oslo

og

Avdeling for sykepleierutdanning

Høgskolen i Oslo og Akershus

\section{Morten Magelssen}

Senter for medisinsk etikk

Universitetet i Oslo

og

Klinikk for medisin

Lovisenberg Diakonale Sykehus

\section{HOVEDBUDSKAP}

Kun et mindretall av medisinstudentene i denne undersøkelsen mener at eutanasi og legeassistert selvmord bør bli lov

Legalisering av legeassistert selvmord ved terminal sykdom hadde størst tilslutning, mens få støttet legalisering ved andre tilstander

Sammenliknet med funn i befolkningsunders $ø$ kelser er en betydelig lavere andel av medisinstudentene for legalisering 
analysene ble utført med khikvadrattest i programmet SPSS (versjon 20). Ettersom studentene kunne gi sin tilslutning til både eutanasi og legeassistert selvmord, overstiger andelene i tabell 2 i sum $100 \%$.

\section{Resultater}

Av totalt 893 studenter på de ni undersøkte kullene var det 531 som besvarte undersøkelsen $(59,5 \%)$. Det er ikke kjent hvor stor andel av studentene som var til stede da skjemaet ble delt ut og dermed ikke hvor mange som hadde mulighet til å delta. Tabell 3 viser karakteristika ved studentene som besvarte undersøkelsen.

For samtlige situasjoner oppgitt i tabell 2 var et mindretall enig $i$ at både eutanasi og legeassistert selvmord bør tillates. Ved terminal sykdom ville $19 \%$ tillate eutanasi og $31 \%$ legeassistert selvmord, mens det for de øvrige situasjonene var færre som ville tillate dette. Samtidig oppga mellom $11 \%$ og $28 \%$ at de var usikre. Hva gjelder de ulike situasjonene svarte gjennomgående flere at legeassistert selvmord heller enn eutanasi burde bli tillatt.

Flere menn enn kvinner svarte at eutanasi og legeassistert selvmord burde bli tillatt ved terminal sykdom (tab 4). Av dem som oppga å være kristne var det færre som mente praksisene burde bli tillatt enn i gruppen studenter som ikke oppga noen religion. Denne tendensen var enda sterkere i gruppen religiøse (uavhengig av hvilken religion) som svarte at religionen var svært eller ganske viktig for dem.

Effekten av variablene kjønn og religion var også til stede i de andre situasjonene, men her var både tallene og forskjellene mindre (data ikke vist). Vi fant ingen tydelige forskjeller i holdninger mellom de ulike studiestedene eller mellom ulike aldersgrupper (data ikke vist), og det var ingen markant forskjell mellom kjønnene når det gjaldt religionstilhørighet eller om de oppga religion som viktig (data ikke vist).

\section{Diskusjon}

Holdningen til legalisering av eutanasi og legeassistert selvmord blant medisinstudentene i denne undersøkelsen er i hovedsak restriktiv. Alternativet som fikk mest støtte, legeassistert selvmord for terminale pasienter, hadde $31 \%$ oppslutning. Det er verdt å merke seg at hele $28 \%$ var usikre stilt overfor dette alternativet. En fornyet og grundig offentlig debatt om temaet kunne tenkes å rekruttere de ubestemte til å ta standpunkt enten for eller mot legalisering.

Sammenliknet med totalbefolkningen er

\section{RAMME 1 \\ Definisjoner (2)}

Eutanasi: En leges intenderte (tilsiktede) drap på en person ved å injisere medikamenter, på personens frivillige og kompetente forespørsel

Legeassistert selvmord: En leges intenderte hjelp til en person i dennes selvmord, ved å skaffe til veie medikamenter som personen kan innta selv, på personens frivillige og kompetente forespørsel

medisinstudentene i vår undersøkelse klart mer restriktive $(6,10,11)$. Forskjeller i holdninger mellom helsepersonell og studenter i helsefagene og den øvrige befolkningen kan skyldes at den første gruppen er formet av tradisjonell profesjonsetikk og den kliniske erfaringen at det er mulig å lindre. Forskjellene kan også være et resultat av begrepsforvirring og usikkerhet $\mathrm{i}$ befolkningen om kliniske, etiske og juridiske skiller. For befolkningen er dessuten spørsmålene hypotetiske og uforpliktende, mens de for helsepersonell og medisinstudenter er direkte knyttet til den daglige yrkesutøvelsen.

Tabell 1 Noen sentrale norske spørreundersøkelser

\section{Gruppe undersøkt}

Vigeland, 1991a (6)

Befolkningen

Medisinstudenter Medisinstudenter
Spørsmålsformulering

«Livet nærmer seg slutten hos en pasient som har en smertefull og uhelbredelig sykdom. Pasienten ber legen om hjelp til å dø. Synes du legen bør ha adgang til å ende pasientens liv på en smertefri måte?»

Tilsvarende spørsmål ved «uhelbredelig lidelse som medfører kroniske smerter, stort ubehag og sterkt begrenset mulighet for livsutfoldelse» (kronisk, ikke-terminal sykdom)

Vigeland, 1991b (7)

Spørsmål som i Vigeland (6)

Spørsmål som i Vigeland (6)
Funn

$56 \%$ enig, $19 \%$ uenig

$31 \%$ enig, $36 \%$ uenig

$22 \%$ enig ved terminal sykdom $15 \%$ enig ved kronisk, ikke-terminal sykdom

$17 \%$ enig ved terminal sykdom, $65 \%$ uenig $4 \%$ enig ved kronisk, ikke-terminal sykdom, $84 \%$ uenig

«Legen bør ha adgang til å avslutte [en uhelbredelig $24 \%$ enig syk persons] liv på en smertefri måte laktiv dødshjelp)»

«Legen bør ha adgang til å hjelpe personen slik at denne selv kan avslutte sitt liv på en smertefri måte (assistert suicid)»

\begin{tabular}{|c|c|c|}
\hline Synovate/Minerva, 2007 (10) & Befolkningen & «Legalisering av aktiv dødshjelp» \\
\hline Synovate/Human-Etisk & Befolkningen & «Legalisering av legeassistert selvmord» \\
\hline
\end{tabular}

Forbund, 2011 (11)
$35 \%$ enig

$67 \%$ «helt» eller «delvis for», $26 \%$ mot

$70 \%$ «helt» eller «delvis enig» $18 \%$ uenig 
Av dem som oppga at religion var viktig, var det klart flere som avviste eutanasi og legeassistert selvmord. Men et betydelig mindretall i denne gruppen svarte ja til dette og går følgelig mot religionenes tradisjonelle standpunkter. Dermed representerer verken religiøs tilhørighet eller religionens viktighet tydelige skillelinjer mellom tilhengere og motstandere av legalisering, noe som er et nytt og interessant funn. I andre norske studier har man ikke funnet kjønnsforskjeller $(8,9)$, men i vår studie var menn mer positive til legalisering enn kvinner.

Det er gjort flere studier av legers, medisinstudenters og den generelle befolkningens holdninger, hvorav noen er presentert i tabell 1 (6-11). Vårt syn er imidlertid at alle norske holdningsundersøkelser på feltet i ulik grad er beheftet med svakheter. Begrepsbruken og spørsmålsformuleringene er ofte upresise og ladet til fordel for en positiv innstiling. Derfor mener vi resultatene må tolkes med forsiktighet. Samlet sett synes svakhetene å gi en skjevfordeling der tilslutningen til legalisering overestimeres (13).

En slik effekt bekreftes i en kanadisk studie, der respondentene ble presentert for enten en positiv eller en nøytral beskrivelse av eutanasi (14). Henholdsvis $81 \%$ og $70 \%$ ville regne eutanasi som moralsk akseptabelt. Definisjonene vi benyttet i spørreskjemaet (ramme 1), er ment å være rent deskriptive og ikke verdiladede. Disse er akseptert av både tilhengere og motstandere av eutanasi i Nederland (1).

Norske medisinstudenters holdninger har tidligere vært gjenstand for to studier, Vigelands (7) og Schioldborgs (9). De benyttet nokså like spørsmålsformuleringer, som vi mener er uheldige. Vi trekker her frem Schioldborg som eksempel (9): «En person har en smertefull, uhelbredelig og dødelig sykdom. Livet nærmer seg slutten og han/ hun har et veloverveid ønske om å dø, og ber om hjelp til dette. Hvor enig/uenig er du i at legen bør ha adgang til å avslutte denne personens liv på en smertefri måte (aktiv dødshjelp)?»

Vi ser fem problemer med dette spørsmålet. For det første gis det inntrykk av at døden er eneste alternativ til en fortsatt smertefull tilværelse. Men moderne palliativ medisin tilbyr effektiv smertelindring for døende $(15,16)$. For det andre er formuleringen «å avslutte denne personens liv på en smertefri måte» upresis. Det kan f.eks. oppfattes som behandlingsbegrensning (her: avslutning av livsforlengende behandling) kombinert med kontinuerlig smertelindring helt frem til dødstidspunktet, noe som klinisk, juridisk og etisk er vesensforskjellig fra bruken av medikamenter for å ta liv. For det tredje er ordet «smertefri» normativt positivt ladet og kan derfor «presse» respon-

Tabell 2 Ulike situasjoner der studentene ble bedt om å vurdere om eutanasi og/eller legeassistert selvmord bør bli tillatt. Det var ikke mulig å svare ja til eutanasi og samtidig svare nei til legeassistert selvmord, men det var mulig kun å svare ja til sistnevnte

\begin{tabular}{|c|c|c|c|c|c|c|c|}
\hline \multirow{3}{*}{$\begin{array}{l}\text { Situasjon } \\
\text { Ved terminal sykdom }\end{array}$} & \multicolumn{7}{|c|}{ Svaralternativer, antall (\%) } \\
\hline & \multicolumn{2}{|c|}{$\begin{array}{c}\text { Eutanasi } \\
\text { bør bli tillatt }\end{array}$} & \multicolumn{2}{|c|}{$\begin{array}{l}\text { Legeassistert } \\
\text { selvmord bør } \\
\text { bli tillatt }\end{array}$} & \multicolumn{2}{|c|}{$\begin{array}{c}\text { Verken eutanasi } \\
\text { eller legeassistert } \\
\text { selvmord bør } \\
\text { bli tillatt }\end{array}$} & Vet ikke \\
\hline & 102 & (19) & 164 & (31) & 217 & $(41)$ & 145 (28) \\
\hline $\begin{array}{l}\text { Ved kronisk sykdom hos } \\
\text { pasienter som ikke er døende }\end{array}$ & 11 & (2) & 26 & (5) & 402 & (77) & $94 \quad(18)$ \\
\hline $\begin{array}{l}\text { Ved alvorlige og permanente } \\
\text { skader etter ulykker }\end{array}$ & 18 & (3) & 39 & (7) & 361 & (69) & 125 \\
\hline Ved psykiatrisk sykdom & 5 & (1) & 8 & (2) & 446 & (85) & 71 (14) \\
\hline $\begin{array}{l}\text { Ved livstretthet uten } \\
\text { medisinsk lidelse }\end{array}$ & & $(0,4)$ & 2 & $(0,4)$ & 469 & (89) & $56 \quad(11)$ \\
\hline
\end{tabular}

denten i aksepterende retning. For det fjerde er smerter og annen somatisk lidelse ikke blant de viktigste årsakene til forespørsler om eutanasi og legeassistert selvmord der dette er tillatt. I stedet dominerer psykososiale faktorer som tap av autonomi, opplevd tap av verdighet, håpløshet, redusert evne til å delta $\mathrm{i}$ aktiviteter som gir livet mening og frykten for generelt forfall $(4,17$, 18). Og for det femte mener vi formuleringen «avslutte denne personens liv på en smertefri måte» er en eufemistisk beskrivelse av et medikalisert drap.

Det er vanskelig å si noe om en eventuell utvikling i medisinstudenters holdninger over tid med utgangspunkt $\mathrm{i}$ disse to norske studiene $(7,9)$. Vi har dokumentert lavere tilslutning enn begge disse, men det kan skyldes ulik spørsmålsformulering, annen begrepsbruk og andre situasjonsbeskrivelser. Vårt resultat kan også være påvirket av den betydelig økte kvinneandelen på medisinstudiet $\mathrm{i}$ de senere år. Kvinner er $\mathrm{i}$ vår studie mindre aksepterende til eutanasi og legeassistert selvmord enn menn, og siden kvinner nå utgjør omtrent to tredeler av medisinstudentene, kan dette ha medført lavere aksept for disse praksisene blant medisinstudenter generelt.

\section{Styrker og begrensninger ved studien}

I utformingen av spørreskjemaet la vi vekt på å unngå ladede formuleringer, først og fremst ved å benytte internasjonalt anerkjente nøytrale betegnelser. Vi mener derfor at denne undersøkelsen er et viktig korrektiv til eldre undersøkelser. Det kan være en svakhet at begrepene som ble benyttet $\mathrm{i}$ beskrivelsen av situasjonene - som «terminal», «alvorlige og permanente skader» og «ulykker» - ikke var nærmere definert, noe som åpnet for fortolkning hos respondentene.
Bare studenter som var til stede på forelesning fikk anledning til å delta, noe som kan ha gitt en utvalgsskjevhet. I tillegg kan det ha foregått en seleksjon fordi noen studenter valgte å la være å svare. Studien ble gjennomført ved de fire norske medisinske fakultetene og er dermed ikke rettet mot den store andelen norske medisinstudenter i utlandet. Det må antas at holdninger til eutanasi og legeassistert selvmord påvirkes av

Tabell 3 Generelle karakteristika ved respondentene ( $N=531)$

$\begin{array}{lll}\text { Karakteristika } & \text { Antall } & (\%) \\ \text { Kjønn, } \mathrm{n}=\mathbf{5 2 8} & & \\ \text { Kvinner } & 346 & (66) \\ \text { Menn } & 182 & (34)\end{array}$

Religion, $\mathrm{n}=517$

$\begin{array}{lrr}\text { Ingen religion } & 276 & \text { (53) } \\ \text { Kristne } & 211 & \text { (41) } \\ \text { Muslimer } & 15 & \text { (3) } \\ \text { Annen religion } & 15 & \text { (3) }\end{array}$

Religionens betydning

for respondenten, $n=239$

$\begin{array}{lcc}\text { Svært viktig } & 66 & (28) \\ \text { Ganske viktig } & 44 & (18) \\ \text { Litt viktig } & 94 & \text { (39) } \\ \text { Ikke viktig } & 35 & \text { (15) }\end{array}$


Tabell 4 Medisinstudentenes meninger om legalisering av eutanasi og legeassistert selvmord ved terminal sykdom. Holdningene er sammenliknet med hensyn til kjønn, religion og religionens betydning

De kategoriske variablene som sammenliknes, antall (\%)

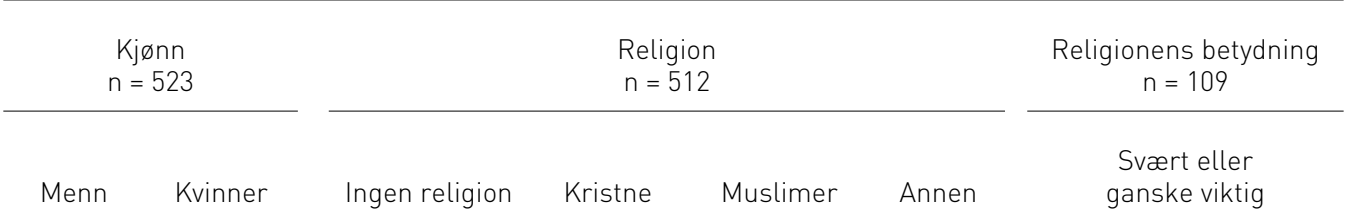

Eutanasi ved terminal sykdom ${ }^{1,2,3}$

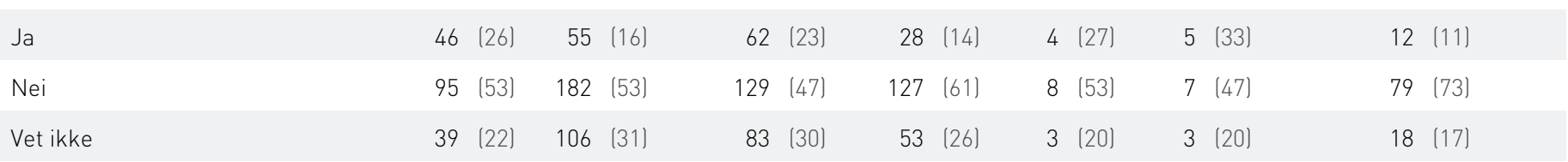

Legeassistert selvmord ved terminal sykdom 4 , 5, 6

\begin{tabular}{llllllllllllllllllll} 
Ja & 69 & $(38)$ & 92 & $(27)$ & 102 & $(37)$ & 47 & $(23)$ & 4 & $(27)$ & 6 & $(40)$ & & 18 & $(17)$ & \\
Nei & 72 & $(40)$ & 145 & $(42)$ & 89 & $(33)$ & 108 & $(52)$ & 8 & $(53)$ & 6 & $(40)$ & & 73 & $(67)$ & & \\
Vet ikke & 39 & $(22)$ & 106 & $(31)$ & 83 & $(30)$ & 53 & $(26)$ & 3 & $(20)$ & 3 & $(20)$ & & 18 & $(17)$ & \\
\hline
\end{tabular}

${ }^{1}$ Menn versus kvinner, $p=0,01$

${ }^{4}$ Menn versus kvinner, $p=0,01$

2 Respondenter uten versus med religion, $p=0,01$

${ }^{5}$ Respondenter uten versus med religion, $p<0,001$

${ }^{3}$ Respondenter som angir høy versus lav viktighet av religion, $p=0,001 \quad{ }^{6}$ Respondenter som angir høy versus lav viktighet av religion, $p<0,001$

den medisinske tradisjonen og kulturen i landet der man studerer.

Spørreskjemaet var utformet slik at den som ga sin tilslutning til eutanasi, samtidig aksepterte legeassistert selvmord for samme indikasjon. Dette ble gjort for å redusere kompleksiteten. Konsekvensen er at eventuelle respondenter som for en gitt indikasjon finner eutanasi, men ikke legeassistert selvmord, akseptabelt, ikke har kunnet formidle dette. Det var imidlertid mulighet til å svare at man for en gitt indikasjon aksepterte legeassistert selvmord, men avviste eutanasi. Både blant helsepersonell og fagetikere er det vanlig enten å se legeassistert selvmord som moralsk mindre problematisk enn eutanasi eller å betrakte dette som moralsk ekvivalente fenomener (19). Det er også kjent fra holdningsundersøkelser i Norge og $\mathrm{i}$ andre land at betydelig flere godtar legeassistert selvmord enn eutanasi (9).

\section{Konklusjon}

I denne studien mener flertallet av medisinstudentene enten at eutanasi og legeassistert selvmord ikke bør tillates eller ikke hadde noen bestemt oppfatning. Et mindretall var åpne for praksisene ved terminal sykdom. Spørreskjemaet er basert på internasjonalt anerkjente definisjoner. Disse bør benyttes i fremtidige studier, noe som også vil lette sammenlikningen av resultater nasjonalt og globalt. Det er etter vårt syn dessuten behov for nye studier omkring norske legers og sykepleieres holdninger og praksis i forbindelse med temaet.

\section{Magnus Andreas Nordstrand (f. 1986)}

er medisinstudent ved Universitetet i Oslo og studerer religion, livssyn og etikk ved Fjellhaug Internasjonale Høgskole.

Forfatter har fylt ut ICMJE-skjemaet og oppgir ingen interessekonflikter.

\section{Sven Jakob Nordstrand (f. 1988)}

er medisinstudent ved Universitetet i Oslo. Forfatter har fylt ut ICMJE-skjemaet og oppgir ingen interessekonflikter.

\section{Lars Johan Materstvedt (f. 1960)}

er dr.art. og professor i filosofi ved Institutt for filosofi og religionsvitenskap, Norges teknisknaturvitenskapelige universitet. Han har vært forsker i Kreftforeningen og leder av The Ethics Task Force on Palliative Care and Euthanasia, European Association for Palliative Care (EAPC). Forfatter har fylt ut ICMJE-skjemaet og oppgir ingen interessekonflikter.

\section{Per Nortvedt (f. 1952)}

er professor og leder av Senter for medisinsk etikk, Universitetet i Oslo. Han er også undervisningsleder for fagområdet medisinsk etikk ved medisinstudiet i Oslo.

Forfatter har fylt ut ICMJE-skjemaet og oppgir ingen interessekonflikter.

\section{Morten Magelssen (f. 1978)}

er lege ved Lovisenberg Diakonale Sykehus og ph.d.-stipendiat ved Senter for medisinsk etikk, Universitetet i Oslo.

Forfatter har fylt ut ICMJE-skjemaet og oppgir ingen interessekonflikter.

\section{Litteratur}

1. Griffiths J, Weyers H, Adams M. red. Euthanasia and law in Europe. Oxford: Hart Publishing, 2008

2. Materstvedt LJ, Clark D, Ellershaw J et al. Euthanasia and physician-assisted suicide: a view from an EAPC Ethics Task Force. Palliat Med 2003; 17. 97-101.

3. Materstvedt LJ, Førde R. Fra aktiv og passiv dødshjelp til eutanasi og behandlingsbegrensning. Tidsskr Nor Legeforen 2011; 131: 2138-40.

4. Materstvedt LJ. Palliative care ethics: the problems of combining palliation and assisted dying. Progr Palliat Care 2013; 21: 158-64.

5. Vermont governor signs assisted-suicide bill. CBSNEWS 20.5.2013. www. cbsnews.com/ 8301-201_162-57585348/vermont-governorsigns-assisted-suicide-bill/ (3.7.2013).

6. Vigeland K. Holdning til aktiv voluntær eutanasi. Tidsskr Nor Lægeforen 1991; 111: 460-3. 
7. Vigeland K. Holdninger til voluntær, aktiv dødshjelp blant studenter. Nord Psykol 1991; 43: 1-16.

8. Førde R, Aasland OG, Falkum E. The ethics of euthanasia - attitudes and practice among Norwegian physicians. Soc Sci Med 1997; 45: 887-92.

9. Schioldborg P. Studenters holdninger til aktiv dødshjelp, assistert suicid og foreslått lovendring. Tidsskr Nor Lægeforen 2000; 120: 2283-8.

10. Flertall for aktiv dødshjelp. Minerva (nettutgaven) 18.9.2007. www.minervanett.no/f lertall-for-aktiv-ddshjelp/ (21.3.2013)

11. Kosberg N. Aktiv dødshjelp - spørreundersøkelse og drøfting. Oslo: Oslo fylkeslag. Human-Etisk Forbund, 2011.

12. Jacobsen KA, red. Bioetikk i verdensreligionene. Oslo: Abstrakt forlag, 2010

13. Materstvedt LJ, Kaasa S. Euthanasia and physician-assisted suicide in Scandinavia - with a conceptual suggestion regarding international research in relation to the phenomena. Palliat Med 2002; 16: 17-32.

14. Marcoux I, Mishara BL, Durand C. Confusion between euthanasia and other end-of-life decisions: influences on public opinion poll results. Can J Public Health 2007; 98: 235-9.

15. Ventafridda V, Tamburini M, Caraceni A et al. A validation study of the WHO method for cancer pain relief. Cancer 1987; 59: 850-6.

16. Caraceni A, Hanks G, Kaasa S et al. Use of opioid analgesics in the treatment of cancer pain: evidence-based recommendations from the EAPC. Lancet Oncol 2012; 13: e58-68.

17. Marquet RL, Bartelds A, Visser GJ et al. Twenty five years of requests for euthanasia and physician assisted suicide in Dutch general practice: trend analysis. BMJ 2003; 327: 201-2.

18. Gamondi C, Pott M, Payne S. Families' experiences with patients who died after assisted suicide: a retrospective interview study in southern Switzerland. Ann Oncol 2013; 24: 1639-44.

19. Pogge TW. From New York City. Palliat Med 2003; 17: 119.

Mottatt 5.4. 2013, første revisjon innsendt 22.5.

2013, godkjent 27.9. 2013. Redaktør: Hanne Støre

valeur. 